\title{
Interannual climate variability helps define the mean state of glaciers
}

\author{
ANDREW G.O. MALONE, ${ }^{1}$ [D ALICE M. DOUGHTY, ${ }^{2}$ DOUGLAS R. MACAYEAL ${ }^{3}$ ๑) \\ ${ }^{1}$ Department of Earth and Environmental Sciences, University of Illinois at Chicago, Chicago, IL, USA \\ ${ }^{2}$ Department of Geology, Bates College, Lewiston, ME, USA \\ ${ }^{3}$ Department of the Geophysical Sciences, University of Chicago, Chicago, IL, USA \\ Correspondence: Andrew G.O. Malone <amalone@uic.edu>
}

\begin{abstract}
Changes in glacier length and extent are indicators of contemporary and archives of past climate changes, but this common climate proxy presents a challenge for inferring a climate signal. Modeling studies suggest that length fluctuations can occur due to interannual climate variability within an unchanging mean climate and that changes in interannual climate variability can also drive changes in average length. This paper quantifies the impacts of interannual climate variability on average glacier length and mass balance, using a flowline model coupled to a simplified mass-balance model. Results illustrate that changes in the magnitude of interannual temperature variability can non-linearly affect the mean glacier length through a mass-balance asymmetry between warm and cold years. This asymmetry is present in models where melt only initiates after a temperature threshold is crossed. Glaciers susceptible to this asymmetry can be identified based on the shape of their massbalance profiles. The presence of mass-balance asymmetries in glaciological databases is evaluated, but current records are too short for high statistical resolving power. While the asymmetry in this study can affect the average length and mass-balance, its impacts are small, and paleoclimate interpretations from glacier-length changes are likely not notably influenced by this process.
\end{abstract}

KEYWORDS: climate change, glacier fluctuations, glacier modeling, mountain glaciers, paleoclimate

\section{INTRODUCTION}

Contemporary glacial retreat is widely regarded as evidence of anthropogenic climate change (Vaughan and others, 2013; Zemp and others, 2015; Roe and others, 2017) and geologic records of past glacial extents are utilized as archives of past climate changes (Porter, 1975; Lowell, 2000; Anderson and Mackintosh, 2006; Doughty and others, 2013). Local meteorology and glacier geometry dictate surface mass balance, and surface mass balance and mass transport within the glacier determine the length (Oerlemans, 2001; Cuffey and Paterson, 2010). Long-term changes in local meteorology (i.e., climate change) thus reflect themselves in glacier-length changes, providing a potentially useful climate proxy in the absence of direct measurements of climatic variables.

Snow and ice accumulation and the surface energy balance dictate mass balance (Oerlemans, 2001; Cuffey and Paterson, 2010), but changes in glacier length can often be modeled using only two key climate variables: airtemperature and precipitation (Oerlemans, 2005; Leclercq and Oerlemans, 2012). The importance of these two climate variables relative to each other largely depends on a glacier's climate setting, with wetter glaciers being more sensitive to temperature and drier glaciers being more sensitive to precipitation (Oerlemans and Fortuin, 1992; Rupper and Roe, 2008). Seasonality in these two variables can also play a role (Oerlemans and Reichert, 2000; Fujita, $2008 a, b)$. Accounting for possible seasonality changes in analyses can affect the climatological interpretations of past glacier-length changes (Vacco and others, 2009). Thus, records and observations of glacier-length changes are often used to infer past and ongoing climate changes.
Glacier-length fluctuations, however, can also occur in an unchanging climate, complicating climatological interpretations of glacier-length changes. Model results suggest that mass-balance anomalies associated with year-to-year variations in air-temperature and precipitation (i.e., interannual climate variability) can drive glacier-length fluctuations independent of changes in the mean climate (Oerlemans, 2000; Roe and O'Neal, 2009; Huybers and Roe, 2009; Roe and Baker, 2014). Thus, climatological interpretations of glacier-length changes are a statistical exercise of disentangling the portion that could be caused by length fluctuations due to interannual climate variability from the portion that requires a change in the average glacier length (Roe, 2011; Anderson and others, 2014; Roe and others, 2017; Herla and others, 2017). Changes in average glacier length, however, are usually associated with changes in the mean climate, but a portion of average length changes could also be due to changes in interannual climate variability. Farinotti (2013) and Malone and others (2015), using different numerical modeling techniques, find that the mean length of a glacier retreats upslope as the magnitude of interannual climate variability increases. Thus, the role of interannual climate variability on the average length and mass balance of glaciers warrants further investigation.

The aim of this study is to quantify the effects of interannual climate variability (henceforth referred to as just interannual variability) on the average length and mass balance of glaciers (i.e., their mean state). Changes in average glacier length and mass balance due to changes in interannual variability are quantified using idealized numerical modeling. Studies are conducted for glaciers in three different climate settings, spanning several different types of glaciers. For all 
three glaciers, the mean state is partially determined by the magnitude of interannual variability, due to a mass-balance asymmetry between warm and cold years. This asymmetry is identified and its presence in observational and modeling studies is discussed. The ability to detect mass-balance asymmetries in the glaciological record is evaluated, and the impact of this mass-balance asymmetry on paleoclimate reconstructions is discussed.

\section{METHODS}

To simulate the transient and average glacier-length response to interannual variability, a shallow ice 1-D flowline model is coupled to a simplified model for surface mass balance. Similar approaches have been used to simulate glacierlength response to climate change and interannual variability (Oerlemans and others, 1998; Oerlemans, 2000; Anderson and Mackintosh, 2006; Roe and O'Neal, 2009). Each model and the experiments conducted are described below.

\subsection{Flowline model}

Ice dynamics are simulated using a 1-D shallow-ice flowline model, which has been shown to capture ice deformation and sliding behavior of mountain glaciers (Oerlemans, 1986). The model requires two inputs: (1) topographic information about the valley and (2) surface mass balance. For topography, an idealized valley geometry is used with a constant bedrock slope (results are shown here for a $10^{\circ}$ slope) and constant valley width. Surface mass balance is calculated using a simplified mass-balance model (see Section 2.2).

The governing equation for the 1-D flowline model is mass continuity for a constant density fluid constrained to a constant width:

$$
\frac{\partial H}{\partial t}=-\frac{\partial}{\partial x}(u H)+b
$$

where $H$ is the thickness of the glacier at a given point along the flowline, $x, h$ is the height of the glacier surface above a datum, $t$ is time, $b$ is the surface mass balance, and $u$ is the sum of the deformation velocity $\left(u_{\mathrm{d}}\right)$ and sliding velocity $\left(u_{\mathrm{s}}\right)$ at the point. Velocity relationships follow the form from Oerlemans (1997):

$$
\begin{aligned}
& u_{\mathrm{d}}=f_{\mathrm{d}} H \tau^{3} \\
& u_{\mathrm{s}}=f_{\mathrm{s}} H^{-1} \tau^{3}
\end{aligned}
$$

where $f_{\mathrm{d}}$ and $f_{\mathrm{s}}$ are the parameters for deformation and sliding, respectively, $\tau$ is the driving stress $(\rho g H(\partial h / \partial x)), g$ is the acceleration due to gravity, $\rho$ is the ice density, and $\partial H / \partial x$ is the slope of the glacier surface. Equation (1) is solved using the Crank-Nicholson method with a time step of 1/500th of a year and a horizontal resolution of $25 \mathrm{~m}$.

\subsection{Mass-balance model}

A mass-balance profile, which accounts for the variations in ablation/accumulation with elevation (Fig. 1a), is used for the surface mass-balance input into the flowline model. The change in the amount of surface mass loss/gain with elevation is referred to as the mass-balance gradient. For many glaciers, the mass-balance gradient is larger at lower elevations
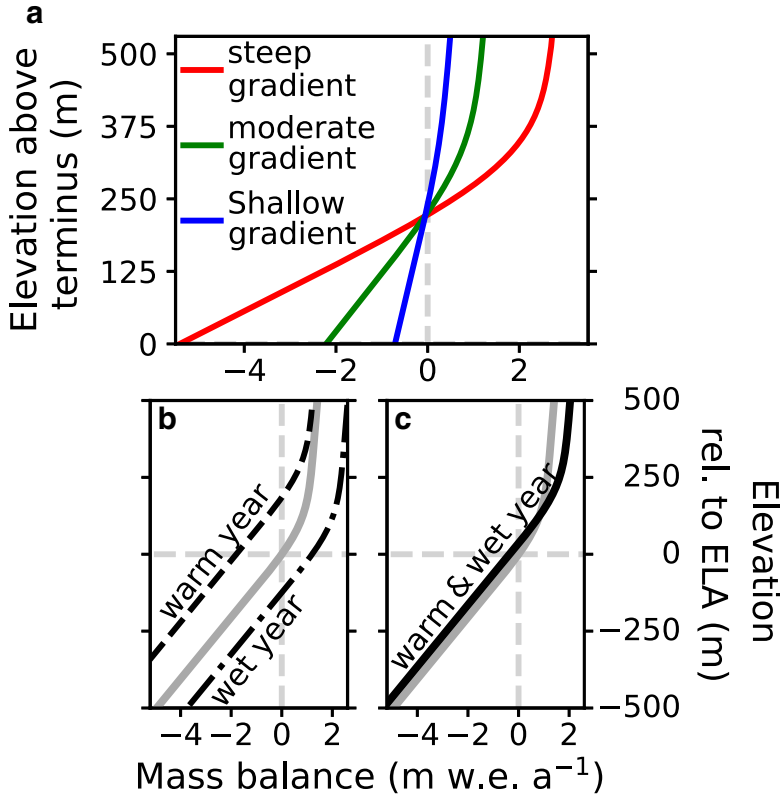

Fig. 1. (a) Mass-balance profiles representative of glaciers in maritime or tropical (steep), mid-latitude continental glacier (moderate), and cold and arid (shallow) regions, (b) mass-balance profile response to a warm year (vertical translation) and wet year (horizontal translation), and (c) mass-balance profile response to a warm and wet year (superposition of the two translations in (b)). The two gradients transition smoothly $100 \mathrm{~m}$ above the equilibrium line altitude (ELA).

and smaller at higher elevations (Rea, 2009; Benn and Evans, 2014). The magnitude of the mass-balance gradient, particularly at lower elevations, also reflects the climate setting. Glaciers in warm maritime or tropical climates have some of the largest mass-balance gradients in their ablation zones (Kaser and Osmaston, 2002). Glaciers in mid-latitude continental climates have smaller mass-balance gradients, and glaciers in arid regions have the smallest gradients (Haefeli, 1962; Kuhn, 1981; Oerlemans, 2001; Kaser, 2001). Experiments are conducted for these three endmember climate settings, as represented by different massbalance profiles (Fig. 1a). The three mass-balance profiles are differentiated henceforth by the steepness of the mass-balance gradient in their ablation zone as follows: (1) steep gradient $\left(2.5 \mathrm{~m}\right.$ w.e. $\left.\mathrm{a}^{-1} 100 \mathrm{~m}^{-1}\right)$,(2) moderate (1.0 m w.e. $\left.\mathrm{a}^{-1} 100 \mathrm{~m}^{-1}\right)$ gradient, (3) shallow gradient (0.3 m w.e. $\mathrm{a}^{-1} 100 \mathrm{~m}^{-1}$ ) (values from Haefeli (1962); Kuhn (1981); Kaser and Osmaston (2002)). For all three profiles, the mass-balance gradient at higher elevations is smaller, being only $0.1 \mathrm{~m}$ w.e. $\mathrm{a}^{-1} 100 \mathrm{~m}^{-1}$. This smaller mass-balance gradient is due to different surface massbalance processes at higher elevations than at lower elevations. Its value largely depends on orographic precipitation and partitioning between rain and snow (Kuhn, 1981; Oerlemans and Hoogendoorn, 1989; Kaser, 2001).

The mass-balance response to interannual variability is simulated by perturbing the mass-balance profile. The shape of a glacier's mass-balance profile remains approximately constant from year-to-year, but the intercept changes due to interannual variability (Meier and Tangborn, 1965; Kaser and others, 2003). The size of the change reflects the magnitude of the interannual anomalies and the equilibrium line altitude (ELA) sensitivity. In this study, only air-temperature and precipitation anomalies are 
explored. The mass-balance response to air-temperature anomalies is simulated by vertical shifts in the massbalance profiles (Fig. 1b). This method has been used to forecast the length evolution of Zongo Glacier (Bolivia) through the 21st century (Réveillet and others, 2015). The massbalance response to precipitation anomalies is simulated by horizontal shifts in the mass-balance profiles (Fig. 1b). This method assumes that anomalous precipitation is added equally to all elevations, which is consistent with previous studies on glacier-length responses to interannual variability Roe and O'Neal (2009); Huybers and Roe (2009); Roe and Baker (2014)). In total, the mass-balance response to anomalies in air-temperature and precipitation is the superposition of the vertical and horizontal shifts (Fig. 1c).

The magnitude of the mass-balance profile translations defined above partially determines the size of the glacierwide mass-balance anomaly. The magnitude of the vertical translation is equal to the product of the air-temperature anomaly and the ELA sensitivity to temperature. Réveillet and others (2015), who apply this vertical translation method to Zongo Glacier (Bolivia), use an observationally derived ELA sensitivity to temperature of $150 \pm 30 \mathrm{~m}^{\circ} \mathrm{C}^{-1}$; In this study, the ELA sensitivity to temperature is assumed to be the inverse of the lapse rate, which is consistent with Sagredo and others (2014) for how ELA sensitivity to temperature varies regionally. A lapse rate of $6.5^{\circ} \mathrm{C} \mathrm{km}^{-1}$ is used for all simulations, producing an ELA sensitivity to temperature of $\sim 150 \mathrm{~m}^{\circ} \mathrm{C}^{-1}$; . The magnitude of the horizontal translation is equal to the amount of anomalous precipitation. The surface mass-balance response to interannual variability is simulated by perturbing the mass-balance profiles as described above.

\subsection{Experiments: glacier-length response to interannual variability}

The transient and average glacier-length response to interannual variability is simulated for each of the three endmember climate settings. To initialize each experiment, the flowline mode is run to equilibrium with each of the three representative mass-balance profiles. In equilibrium, the initialized glaciers are $3 \mathrm{~km}$ long. To ensure that each glacier is $3 \mathrm{~km}$ long, the ELA is moved vertically. The ELA is closest to the terminus for the glacier with the steepest mass-balance gradient and closest to the summit for the glacier with the shallowest mass-balance gradient. The mass loss at the terminus, however, is largest for the glacier with the steep mass-balance gradient and smallest for glacier with the shallow mass-balance gradient. Using the glacier response time formula from Roe and O'Neal (2009), the response times for the three different mass-balance profiles are: steep, $\tau=12$ years; moderate, $\tau=22$ years; and shallow, $\tau=48$ years. Once the initialization is complete, the mass-balance profiles are perturbed by adding interannual variability into the simulations. The resulting transient simulations are run for 10,100 model years. Analyses are conducted on the final 10,000 years of model output.

The mass-balance profiles are perturbed by interannual air-temperature and precipitation anomalies that are drawn randomly from Gaussian distributions with a prescribed standard deviation ( $1-\sigma$ value). The two climate anomalies are uncorrelated in time from each other. For each model year, the mass-balance profile is perturbed by that year's air-temperature anomaly and precipitation anomaly, as described in Section 2.2. The timing of air-temperature and precipitation anomalies are the same for all simulations, and different magnitudes of variability are simulated by changing the amplitude of the anomalies. Simulations are conducted with precipitation anomalies with a $1-\sigma$ value of $0.50 \mathrm{~m}$ w.e. $\mathrm{a}^{-1}$ and air-temperature anomalies with $1-\sigma$ values ranging from 0.00 to $1.50^{\circ} \mathrm{C}$, in increments of $0.25^{\circ}$ C $(n=7)$. Additionally, simulations are conducted without precipitation anomalies but air-temperature anomalies with $1-\sigma$ value of $0.50^{\circ} \mathrm{C}(n=1)$. In total, eight transient simulations are conducted for each of the three climate settings (as simulated by the steep, moderate, and shallow mass-balance profiles).

In addition to the effects of interannual variability on the transient and average glacier length, the equilibrium response to a sustained change in the mass-balance profile is quantified. After the model spin-up is complete, the mass-balance profile is instantaneously changed to a new mass-balance profile and then run to equilibrium. The changes to the mass-balance profiles for these equilibrium simulations are discussed in Section 3.1. These equilibrium experiments help isolate the processes linking interannual variability to changes in the mean state.

\section{RESULTS}

\subsection{Interannual variability and the mean state of glaciers}

Interannual variability produces model glacier-length fluctuations around an average length, while also reducing the average length as compared to the spin-up model length without interannual variability (Fig. 2a). For the same timing and magnitude of interannual variability, the magnitude of the transient fluctuations differs (Fig. 2a). The shallow mass-balance gradient glacier has the largest magnitude of length fluctuations, and the moderate mass-balance gradient glacier has the smallest magnitude of length fluctuations (as quantified by the standard deviation of the glacier length time series, $\sigma_{L}$ ). For the shallow, moderate and steep mass-balance gradient glaciers, the length variabilities are: $\sigma_{L}=206,126$ and $131 \mathrm{~m}$. The differences in size and timing of length fluctuations for identical interannual variability stems from two key differences between the glaciers: (1) response time (see Section 2.3 for values) and (2) magnitude of mass-balance variability. Details regarding how these differences can affect the size and timing of transient length fluctuations can be found in Roe and Baker (2014); Roe and others (2017); Mackintosh and others (2017).

The average length around which these glaciers fluctuate, however, is shorter than the $3 \mathrm{~km}$ spin-up length (Table 1). During the first few decades to centuries of the transient simulations, all three glaciers fluctuate on top of a trend of upslope-retreat, with differing retreat rates (Fig. 2a). The steep mass-balance gradient glacier retreats the most $(100 \mathrm{~m})$, followed by the moderate mass-balance gradient glacier $(75 \mathrm{~m})$, and the shallow mass-balance gradient glacier retreats the least $(50 \mathrm{~m})$, for simulations with $25 \mathrm{~m}$ spatial resolution. After the glaciers reach their new average length, they fluctuate around this length for the remainder of the transient simulations.

The average length of all three glaciers is partially determined by interannual climate variability, suggesting that the average mass balance also depends on interannual 


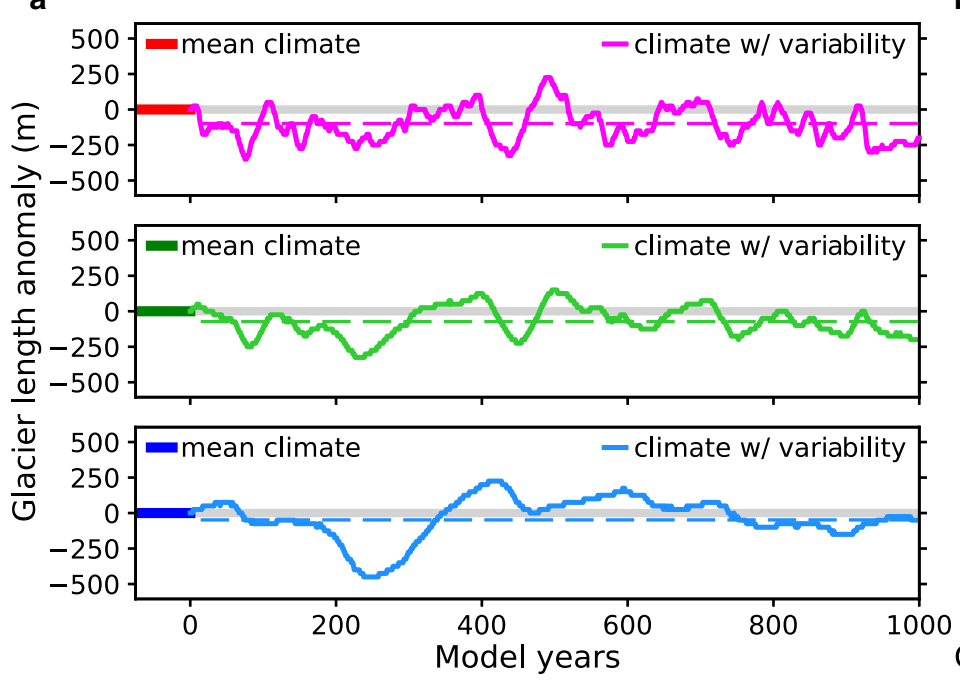

b

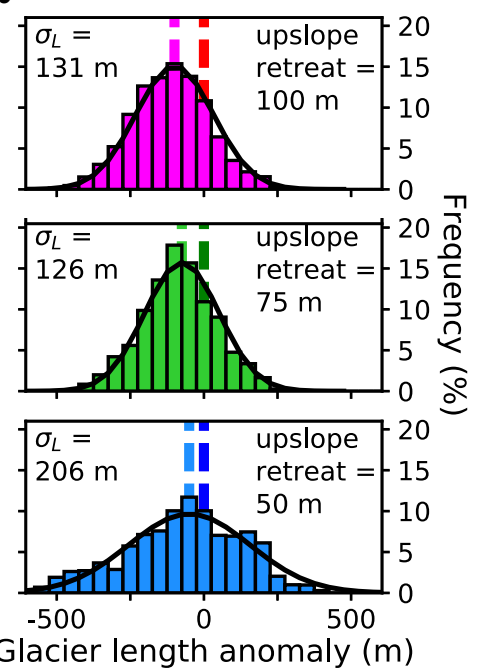

Fig. 2. (a) Glacier-length fluctuations due to interannual variability for the steep mass-balance gradient glacier (top), moderate mass-balance gradient glacier (middle), and shallow mass-balance gradient glacier (bottom) and (b) distribution of glacier-length fluctuations for the transient simulations, including normal distributions (black lines) with the same magnitude of length fluctuations. Length anomalies are relative to the 3km spin-up length. Dashed lines represent the average glacier lengths in (a) and the equilibrium glacier length for the spin-up mass-balance profile (mean climate) and the time-averaged mass-balance profile (mean of climate w/ variability) in (b). All three glaciers are forced by the same timing of interannual variability. Only the first 1000 years of the 10,100-year transient simulations are shown in (a), and the final 10000 years of the transient simulations are used for the histograms and statistics in (b). Results are shown for interannual temperature variability with a $1-\sigma$ value of $0.5^{\circ} \mathrm{C}$ and interannual precipitation variability with a $1-\sigma$ value of $0.5 \mathrm{~m}$ w.e. $\mathrm{a}^{-1}$.

variability. For each climate setting, the time-average (mean) of the mass-balance profiles for the transient simulations has a different shape than the mass-balance profile for the mean climate (i.e., the climate without interannual variability). For the $3 \mathrm{~km}$ spin-up glacier length, these time-averaged massbalance profiles produce negative glacier-wide mass balances; thus driving upslope retreat. To evaluate the role of this change in the mass-balance profile on the average glacier lengths, equilibrium glacier length simulations are conducted using the time-averaged mass-balance profiles as inputs to the flowline model. The equilibrium glacier lengths with the time-averaged mass-balance profiles are the same as the average glacier length from the transient simulations (Fig. 2b), within the model resolution $(25 \mathrm{~m})$. Both the average glacier length and the average massbalance profile are at least partially determined by interannual climate variability, and it is the change in the average mass-balance profile that drives the change in the average glacier length.

\subsection{Relationships between interannual variability and changes in the mean state}

The transient and average response to interannual variability differs depending on whether forced by air-temperature or precipitation interannual variability (Table 1). Consistent with previous studies Roe and O'Neal (2009), the magnitude of glacier-length fluctuations from both air-temperature and precipitation variability $\left(\sigma_{L}\right)$ is roughly the linear combination of length fluctuations from air-temperature variability $\left(\sigma_{L, T}\right)$ and precipitation variability $\left(\sigma_{L, P}\right)$ (i.e., $\sigma_{L}=\sqrt{\sigma_{L, T}^{2}+\sigma_{L, P}^{2}}$ ). For the glacier with the steep mass-balance gradient, $86 \%$ of the standard deviation in glacier length fluctuations is driven by air-temperature variability. For the glacier with the shallow mass-balance gradient, $90 \%$ is driven by precipitation variability. For the glacier with the moderate massbalance gradient, the transient length fluctuations are more evenly partitioned (temperature: 52\%, precipitation: $48 \%$ ). An upslope retreat, and thus a change in the mean state, only occurs when interannual air-temperature variability is included. The size of this retreat is identical to the size when forced with both air-temperature and precipitation variability. Interannual precipitation variability alone does not change the average glacier length. While the transient glacier length fluctuations can be driven by both air-temperature and precipitation interannual variability, we conclude that, to within the spatial resolution of the model $(25 \mathrm{~m})$, changes in the mean state are driven only by interannual air-temperature variability.

Table 1. Transient and average glacier-length response to air-temperature and/or precipitation interannual variability: $\sigma_{T}=0.5^{\circ} \mathrm{C}$ and/or $\sigma_{P}=0.5 \mathrm{~m}$ w.e a $^{-1}$

\begin{tabular}{|c|c|c|c|c|c|c|c|c|c|}
\hline & \multicolumn{3}{|c|}{ Steep } & \multicolumn{3}{|c|}{ Moderate } & \multicolumn{3}{|c|}{ Shallow } \\
\hline & Both & Only temp. & Only precip. & Both & Only temp. & Only precip. & Both & Only temp. & Only precip. \\
\hline$\sigma_{L}(\mathrm{~m})$ & 131 & 122 & 49 & 126 & 91 & 88 & 206 & 65 & 196 \\
\hline upslope retreat $(\mathrm{m})$ & 100 & 100 & 0 & 75 & 75 & 0 & 50 & 50 & 0 \\
\hline
\end{tabular}

$\sigma_{L}$ is the standard deviation of the glacier length time series and the upslope retreat is how much shorter the average glacier length is compared to the 3 km spinup length. 


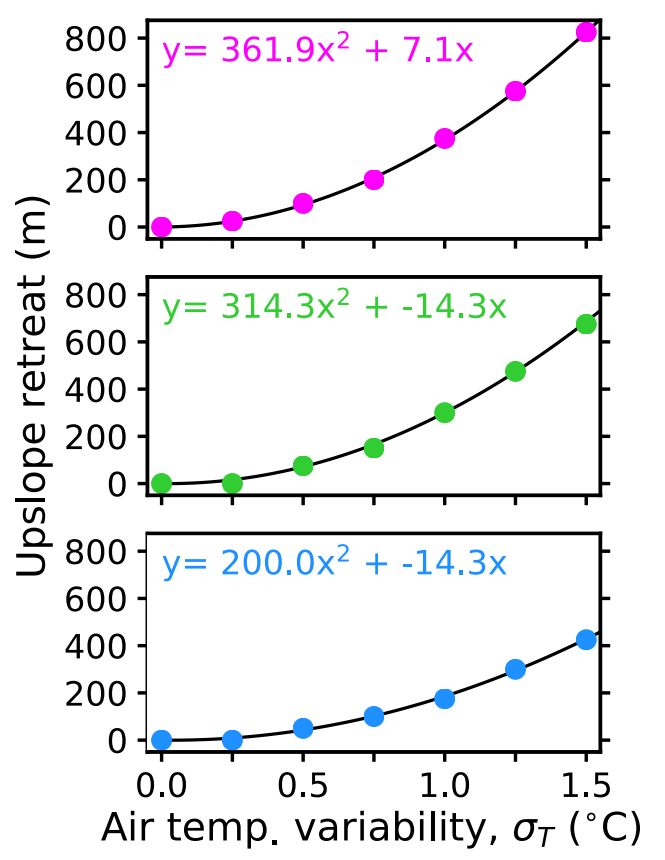

Fig. 3. Upslope retreat due to the addition of different magnitudes of interannual temperature variability for the steep mass-balance gradient glacier (top), moderate mass-balance gradient glacier (middle) and shallow mass-balance gradient glacier (bottom). Quadratic models relating upslope retreat and the magnitude of interannual variability are included.

The size of the upslope retreat increases quadratically with increased interannual air-temperature variability (Fig. 3). The average length of the steep mass-balance gradient glacier retreats $100 \mathrm{~m}$ if the magnitude of the interannual temperature variability (quantified by a $1-\sigma$ value) increases from 0.5 to $0.75^{\circ} \mathrm{C}$. For this same glacier starting in a noisier climate, an increase in the interannual temperature variability from 1.0 to $1.25^{\circ} \mathrm{C}$ causes a $200 \mathrm{~m}$ retreat. For the shallow mass-balance gradient glacier, the same quadratic relationship holds, but the size of retreat is less. For the two scenarios given above, the retreat is 50 and $125 \mathrm{~m}$. The moderate massbalance glacier falls between these two extremes but closer to the steep mass-balance gradient limit. Three key factors affect how the mean state of a glacier responds to changes in interannual air-temperature variability: (1) climate setting of a glacier, (2) how noisy the interannual air-temperature variability is before the change in its magnitude and (3) the size of the change in interannual air-temperature variability. Changes in the mean glacier state due to changes in interannual variability are most acute for large changes in air-temperature variability at glaciers with steep mass-balance gradients that are found in climates with large interannual air-temperature variability.

\section{DISCUSSION}

\subsection{A mechanism for upslope retreat: mass-balance asymmetries}

The results from the idealized modeling presented here suggest that interannual air-temperature variability partially defines the mean state of a glacier. Interannual air-temperature variability affects the mean state through a massbalance asymmetry between warm and cold years: more mass is lost on a warm year than gained on a cold year of equal magnitude. Near the transition in mass-balance gradients (100 $\mathrm{m}$ above the ELA), a warm year produces a larger negative mass-balance perturbation than a positive perturbation during a cold year (Fig. 4). This mass-balance mismatch between warm and cold years near the point-of-inflection in the mass-balance profile produces an asymmetry that grows linearly as air-temperature variability increases (Fig. 4). At the same time, the area over which this asymmetry occurs increases as air-temperature variability increases. The area increases linearly with increasing air-temperature variability because of the method implemented for perturbing the mass-balance profiles and the constant width valley geometry (Section 2.2). The resulting asymmetry scales with the product of these two processes, producing a quadratic mass-balance asymmetry with increasing air-temperature variability. The quadratic mass-balance asymmetry is evident in the form of the upslope retreat of the glacier (Fig. 3).

This asymmetry is the logical conclusion of a non-linear mass-balance profile that responds linearly to air-temperature perturbations. A linear mass-balance profile would not produce a mass-balance asymmetry and would not affect the mean state (Appendix). The size of the asymmetry increases as the difference in the mass-balance gradients between the upper and lower elevations (i.e., the amount of curvature in the mass-balance profile) increases and the amount of interannual air-temperature variability increases (Fig. 4). Additionally, the elevation range over which massbalance gradients transition affects the asymmetry. The smaller the elevation range, the larger the curvature and the greater the asymmetry. Interannual precipitation variability does not influence the mean state since in this study accumulation anomalies respond symmetrically to precipitation perturbations.

Surface mass-balance asymmetries from short-term climate variability are noted in both observational and modeling studies. Bradley and England (1978) illustrate that the long-term mass balance of the Devon Ice Cap (Canada) can be strongly influenced by one or a few warm years. The asymmetry in their study is a curvilinear relationship between mass balance and temperature - negative massbalance anomalies can grow almost limitlessly as hotter years produce more melt but there is a limit to positive mass-balance anomalies on colder years. Farinotti (2013)

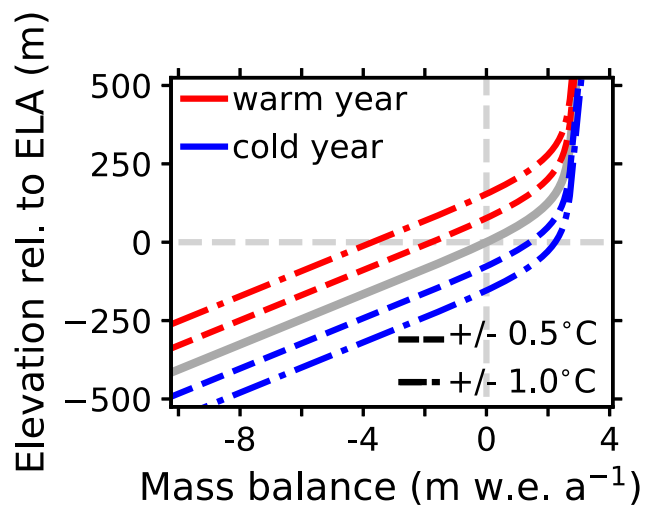

Fig. 4. Mass-balance response to different signs and magnitudes of air temperature anomalies. The vertical displacements in the profile are symmetric to warm and cold anomalies, as prescribed by the methods, but the glacier-wide mass-balance response is asymmetric. 
illustrates that increased temperature variability (at timescales from daily to yearly) can reduce ice volume and cause upslope retreat of Rhonegletcher (Switzerland). The asymmetry in his model is the one inherent in any temperature-threshold mass-balance model - melt only occurs above a temperature threshold (e.g., $0^{\circ} \mathrm{C}$ ). In temperaturethreshold mass-balance models (e.g., positive-degree-day models) warm temperature anomalies increase the melt rate and duration of melt season in regions where melting is common. Warm temperature anomalies can also initiate melt in portions of the glacier where melt is uncommon. The net effect is that warm years can produce more mass loss that can be compensated for during cold years. Studies using temperature-threshold models often find asymmetric mass-balance responses to warming and cooling (Braithwaite and Zhang, 2000; Engelhardt and others, 2015). At the heart of these previously proposed mechanisms is the principle that negative mass-balance anomalies from warm air-temperature, cannot be compensated by positive mass-balance anomalies from cool air-temperatures.

The asymmetry mechanism proposed in this study also relies on this inability to offset melt. The smaller massbalance gradient at the upper elevations reflects minimal influence by surface melting, while the larger gradient at lower elevations reflects changes in available melt energy with elevation (Kuhn, 1981; Oerlemans and Hoogendoorn, 1989; Kaser, 2001). During a warm year, portions of higher elevations are influenced by the larger mass-balance gradient, and melt occurs where melt is uncommon. Melting at lower elevations is also amplified. During an equally cold year, portions of lower elevations are influenced by the smaller mass-balance gradient, and melt is somewhat reduced where it is usually common. Slightly more accumulation also occurs at elevations where melt is rare, the value of which is defined by the mass-balance gradient at higher elevations. Excess accumulation and decreased ablation on the cold year, however, cannot compensate for the excess mass loss on the equally warm year. The mechanism identified in this study also relies on an asymmetry between mass loss on warm years and mass gain on cold years, a process commonly identified in the above-referenced modeling and observational studies. Framing the mechanism in terms of curvature in the mass-balance profile provides two easily observable glaciological features to identify glaciers that are highly susceptible to this asymmetry: (1) glaciers with mass-balance gradients with large curvature and (2) glaciers with large interannual ELA variability (a proxy for large airtemperature variability).

Additional mechanisms for nonlinear mass-balance responses to climate perturbations exist. For example, valley geometries with more area at higher elevations than lower elevations, produce mass-balance responses to airtemperature that increase cubicly (Roe and Lindzen, 2001). For the constant-width valley in this study, however, a mass-balance asymmetry due to air-temperature anomalies will only emerge if there is curvature in the mass-balance profile (see Appendix). Additionally, potential nonlinearities exist for precipitation, specifically through the role that airtemperature plays in dictating its phase. This interplay is not a process included in this study, and it has been shown to influence mass-balance sensitivity to climate perturbations (Fujita, 2008a,b). The phase of precipitation, however, may not produce a mass-balance asymmetry for accumulation since a cold, wet year can be balanced by a cold, dry year and a warm, wet year can be balanced by a warm, dry year. If interannual variability is symmetric, the accumulation response will also be symmetric and the mean state will be unaffected. The role that the phase of precipitation plays in dictating the albedo and thermal conductivity of a glacier's surface (Hock, 2005) may produce a mass-balance asymmetry for ablation. These mechanisms cannot be explored using the methods of this study, and for some glaciers (e.g., tropical glaciers) the phase of precipitation may play a central role in initiating melt (Mölg and Hardy, 2004; Favier and others, 2004). Precipitation events can also affect ablation through the ways in which cloud cover influences surface energy budgets, in particular, longwave radiation (Hock, 2005), which could introduce additional nonlinear mass-balance responses to climate variability. Previous studies using higher complexity mass-balance models, however, suggest that changing the magnitude of short-term precipitation variability does not affect the average glacier length (Farinotti, 2013; Malone and others, 2015). Many non-linearities are inherent in glacier mass balance, although not all non-linearities produce asymmetries that can affect the mean state. In this study, an asymmetry emerges when melt initiates in regions where melt is uncommon, which cannot be compensated for on a cold year. Potential additional non-linearities exist that could produce asymmetries and warrant further study.

\subsection{Mass-balance asymmetries and the glaciological record}

Mass-balance asymmetries stemming from interannual temperature variability should be ubiquitous for glaciers with curvature in their mass-balance profiles, and they should be more acute the larger the curvature and the greater the interannual air-temperature variability. For many glaciers, their mass-balance profiles possess curvature (e.g., World Glacier Monitoring Service (Zemp and others, 2013) or Benn and Evans (2014), Fig. 3.26), and analysis of multiple glaciological databases indicates that many glaciers have larger mass-balance gradients in their ablation zones than accumulation zones (Rea, 2009). The model output from this study can help assess whether these mass-balance asymmetries are easily detectable in the glaciological record. The mass-balance output from the transient simulations for the glaciers with steep and moderate mass-balance gradients appear to be visually different from a normal distribution (Fig. 5). Despite being forced by normally distributed interannual variability, they demonstrate negative skew and are statistically distinguishable from a normal distribution by either a D'Agostino and Pearson (D'Agostino and Pearson, 1973) or Jarque-Bera test (Jarque and Bera, 1980) (Fig. 5). The mass-balance output for the glacier with the shallow mass-balance gradient, however, is neither visually nor statistically indistinguishable from a normal distribution (Fig. 5). While this asymmetry should be ubiquitous, its presence in the glaciological record may only be resolvable for glaciers highly susceptible to the asymmetry: glaciers with larger curvature in their mass-balance profile in climates with large interannual air-temperature variability.

A recent analysis of the World Glacier Monitoring Service (WGMS) database demonstrates that nearly all of the (detrended) mass-balance time series are indistinguishable from normal distributions (Medwedeff and Roe, 2016). In their analysis, 144 out of 158 glaciers (>91\%) are statistically 


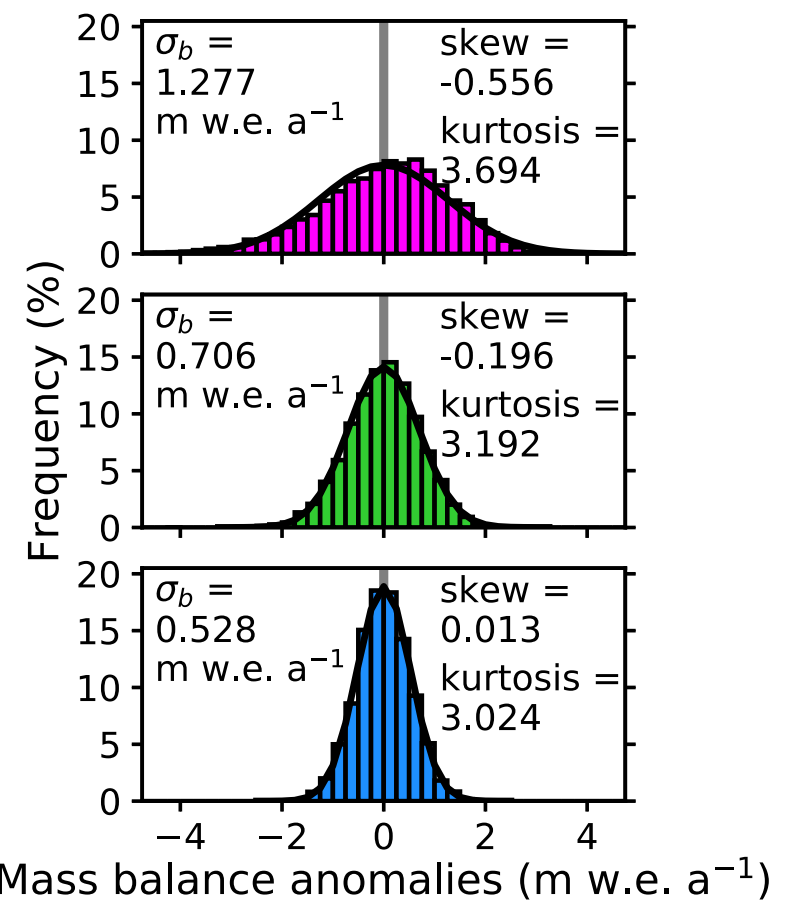

Fig. 5. Distribution of mass-balance anomalies for the steep massbalance gradient glacier (top), moderate mass-balance gradient glacier (middle) and shallow mass-balance gradient glacier (bottom). Normal distributions (black curves) with the same $1-\sigma$ values as the mass-balance times series $\left(\sigma_{b}\right)$ are included. Statistics on the shape of the distribution are also included. The interannual variability is the same as in Fig. 2.

indistinguishable from a normal distribution. For tropical glaciers, which have particularly steep mass-balance gradients at lower altitudes, all $(n=6)$ are indistinguishable (Medwedeff and Roe, 2016). The results of this study, however, suggest that many of the world's glaciers should have skewed mass-balance distributions that should be statistically distinguishable from a normal distribution. The findings from Medwedeff and Roe (2016) may differ from the analysis of the model output from this study since the length of the time series differs drastically (a few decades vs. 10,000 years). The longest mass-balance record in the Medwedeff and Roe (2016) study is 67 years, and for tropical glaciers, it is 21 years. Medwedeff and Roe (2016) note the limited statistical resolving power of the short time series in the WGMS database. Analyses of the model output from this study can help evaluate limitations in the glaciological record.

Using the model output, synthetic mass-balance records are produced that span 10 years, 25 years, 50 years and 100 years. For each time series length, 158 synthetic records are produced. Jarque-Bera tests (Jarque and Bera, 1980) are used to determine how many of the time series are statistically indistinguishable from a normal distribution. This process is repeated 1,000 times, and the mean and standard deviation $(1-\sigma)$ are indicated in Table 2. The ability to statistically resolve the asymmetry increases as the length of the mass-balance record increases. Also, it is more discernible for the glaciers with greater curvature in their massbalance profiles (Table 2). For 25-year records (longer than any in the tropics), the mass-balance asymmetry can only be statistically resolved $\sim 10 \%$ of the time for the glacier with the greatest curvature in its mass-balance profile. The
Table 2. Frequency at which synthetic mass-balance records are statistically indistinguishable from a normal distribution $(p \geq 0.05)$ by a Jarque-Bera test (same interannual variability as in Fig. 2)

\begin{tabular}{lccc}
\hline & \multicolumn{3}{c}{ Percentage of times (mean $\pm 1-\sigma \%)$} \\
\cline { 2 - 4 } Length of record (years) & Steep & Moderate & Shallow \\
\hline 10 & $98.2 \pm 1.1$ & $99.2 \pm 0.7$ & $99.1 \pm 0.7$ \\
25 & $90.7 \pm 2.3$ & $96.2 \pm 1.6$ & $96.9 \pm 1.4$ \\
50 & $81.2 \pm 3.2$ & $93.7 \pm 2.0$ & $96.0 \pm 1.5$ \\
100 & $64.2 \pm 3.8$ & $91.8 \pm 2.2$ & $96.0 \pm 1.6$ \\
\hline
\end{tabular}

resolving power is even less for the glaciers with less curvature in their mass-balance profiles. These analyses suggest that statistically demonstrating mass-balance asymmetries in glaciological databases will be challenging, even if asymmetries are ubiquitous. The analysis of the WGMS (Medwedeff and Roe, 2016) is not inconsistent with the mass-balance asymmetry presented in this study, and mass-balance asymmetries are likely lurking in the databases. As records become longer, mass-balance asymmetries, such as the one identified in this study and others, should become more statistically discernible.

\subsection{Mass-balance asymmetries and interpreting changes in glacier length}

While changes in average glacier length could be driven by changes in interannual air-temperature, this process may not significantly affect paleoclimatological interpretations of glacier-length changes. Even for large changes in interannual air-temperature variability $(25 \%)$, length changes are at most a few hundred meters (Fig. 3). An assessment of changes in interannual air-temperature variability during the Medieval Climate Anomaly and Little Ice Age realized in the Paleoclimate Modeling Intercomparison Project Phase 3 (PMIP3) simulations suggests that interannual air-temperature variability changes are at most a few percent (Yang and Jiang, 2017). Such small changes in interannual air-temperature variability would likely not be noticeable within the spatial resolution of glacier numerical models. Looking further back in time, high-latitude Southern Hemisphere climate variability may have decreased up to $50 \%$ between the Last Glacial Maximum (LGM) and the Holocene Jones and others (2018)). Such a large change in variability might affect LGM paleoclimate reconstructions from glaciers in the mid and high latitudes of the Southern Hemisphere. If temperature variably was substantially elevated during the LGM, then paleoclimate inversions from glacier length changes to changes in climate may somewhat underestimate LGM climate changes, since glaciers may have been smaller than they would be under Holocene-levels of climate variability. For forecasts of glacier evolution over the next century, however, projected changes in interannual air-temperature do not notably affect the forecasts (Farinotti, 2013). The results of this study also suggest that linear models for glacier-length response to climate forcings can accurately capture the dynamics of transient length fluctuations. The length fluctuations due to interannual variability seem to be well captured as a linear combination of the length fluctuations due to air-temperature and due to precipitation (Table 1). While mass-balance asymmetries likely exist and can affect the mean glacier length, they do not seem to 
significantly influence the dynamic response of the glacier length to climate changes or impede efforts to reconstruct past climate using changes in average glacier length.

This study may aid paleoclimate modeling studies by helping initialize models for simulations with interannual climate variability. Paleoclimate reconstructions from changes in glacier length should account for both the portion of length changes that could occur due to interannual variability and the portion that requires a change in the climate (Roe, 2011; Anderson and others, 2014; Roe and others, 2017; Herla and others, 2017). Numerical modeling experiments where both interannual climate variability and changes in the climate are explored often simulate these two scenarios independent of each other, in part because the mean length of the glacier changes with the addition of interannual variability (Malone and others, 2015; Eaves and others, 2019). In this study, for a constant-width valley, the change in the mean length with the addition of interannual variability can be predicted by time averaging the glacier mass-balance profiles from the transient simulations with variability. This time-averaged mass-balance profiles could then be used to initialize the model before running transient simulations with interannual climate variability and changes in the climate.

\section{CONCLUSIONS}

This study demonstrates that interannual climate variability can drive transient glacier-length fluctuations, and also partially determines a glacier's average length and massbalance profile (i.e., its mean state). Interannual variability affects the mean state through a mass-balance asymmetry between warm and cold years that emerges due to curvature in the mass-balance profile. More curvature leads to a larger asymmetry, and this asymmetry grows with increased interannual air-temperature variability. Such asymmetries are also observed for ice sheets (Mikkelsen and others, 2018). Mikkelsen and others (2018) used an ice-sheet model that assumes a mass-balance profile with curvature (Oerlemans, 2003). Glaciers (or ice sheets) whose mean state is dictated in part by stochastic short-term variability undergo noiseinduced drift (Penland, 2003). Evidence of mass-balance asymmetries is hard to statistically demonstrate in databases (e.g., the World Glacier Monitoring Service) since records span only a few decades. As mass-balance records become longer, asymmetries should become more discernible.

For reasonable changes in interannual air-temperature variability, the effect on glacier length is minimal - a few hundred meters at most. These findings, however, may further aid in climatological interpretations of past and present glacier-length changes. Previous paleoclimate reconstructions noting such mass-balance asymmetries have treated the impacts of interannual variability independent from changes to the mean climate (Malone and others, 2015; Eaves and others, 2019). Future research should incorporate the role of interannual temperature variability on the mean state of glaciers for both transient and equilibrium simulations. For simple valley geometry used in this study, the change in the mean state can be predicted by time averaging the mass-balance profiles that include interannual variability. These time-averaged vertical massbalance profiles can provide improved initial conditions for future studies on climatological interpretations of glacierlength changes.

\section{ACKNOWLEDGEMENTS}

We thank an anonymous reviewer for feedback on this manuscript and Gerard Roe for feedback on this and an earlier version of this manuscript. This feedback has greatly improved both the presentation and content of this manuscript. AM's funding was provided by the University of Chicago Department of the Geophysical Sciences and the Office of the Provost at Lawrence University. AD's funding was provided by the New Zealand Government under a New Zealand International Research Doctoral Scholarship and through Victoria University of Wellington, in New Zealand. DRM acknowledges grant support from NSF PLR1443126.

\section{REFERENCES}

Anderson B and Mackintosh A (2006) Temperature change is the major driver of late-glacial and Holocene glacier fluctuations in New Zealand. Geology, 34(2), 121-124

Anderson LS, Roe GH and Anderson RS (2014) The effects of interannual climate variability on the moraine record. Geology, 42(1), 55-58

Benn D and Evans DJ (2014) Glaciers and Glaciation. Routledge, New York, NY, USA

Bradley RS and England J (1978) Recent climatic fluctuations of the Canadian High Arctic and their significance for glaciology. Arct. Alp. Res., 10(4), 715-731.

Braithwaite RJ and Zhang Y (2000) Sensitivity of mass balance of five swiss glaciers to temperature changes assessed by tuning a degree-day model. J. Glaciol., 46(152), 7-14

Cuffey KM and Paterson WSB (2010) The physics of glaciers. Academic Press, Burlington, MA, US

D'Agostino R and Pearson ES (1973) Tests for departure from normality. empirical results for the distributions of b 2 and? $b$. Biometrika, 60(3), 613-622

Doughty AM and 9 others (2013) Evaluation of lateglacial temperatures in the Southern Alps of New Zealand based on glacier modelling at Irishman Stream, Ben Ohau Range. Quat. Sci. Rev., 74, 160-169

Eaves SR, Mackintosh AN and Anderson BM (2019) Climate amelioration during the last glacial maximum recorded by a sensitive mountain glacier in New Zealand. Geology, 47(4), 299-302

Engelhardt M, Schuler TV and Andreassen LM (2015) Sensitivities of glacier mass balance and runoff to climate perturbations in Norway. Ann. Glaciol., 56(70), 79-88

Farinotti D (2013) On the effect of short-term climate variability on mountain glaciers: insights from a case study. J. Glaciol., 59 (217), 992-1006

Favier V, Wagnon P and Ribstein P (2004) Glaciers of the outer and inner tropics: A different behaviour but a common response to climatic forcing. Geophys. Res. Lett., 31(16), L16403, 1-5

Fujita K (2008a) Effect of precipitation seasonality on climatic sensitivity of glacier mass balance. Earth. Planet. Sci. Lett., 276 (1), 14-19

Fujita K (2008b) Influence of precipitation seasonality on glacier mass balance and its sensitivity to climate change. Ann. Glaciol., 48(1), 88-92

Haefeli R (1962) The ablation gradient and the retreat of a glacier tongue. IASH Publication, 58, 49-59

Herla F, Roe GH and Marzeion B (2017) Ensemble statistics of a geometric glacier length model. Ann. Glaciol., 58(75pt2), 1-6.

Hock R (2005) Glacier melt: a review of processes and their modelling. Prog. Phys. Geogr., 29(3), 362-391

Huybers K and Roe GH (2009) Spatial patterns of glaciers in response to spatial patterns in regional climate. J. Clim., 22(17), 4606-4620

Jarque CM and Bera AK (1980) Efficient tests for normality, homoscedasticity and serial independence of regression residuals. Econ. Lett., 6(3), 255-259 
Jones TR and 5 others (2018) Southern hemisphere climate variability forced by northern hemisphere ice-sheet topography. Nature, 554(7692), 351

Kaser G (2001) Glacier-climate interaction at low latitudes. J. Glaciol., 47(157), 195-204

Kaser G and Osmaston H (2002) Tropical Glaciers. Cambridge University Press, Cambridge, UK

Kaser G and 5 others (2003) A manual for monitoring the mass balance of mountain glaciers. Unesco Paris, Paris, France

Kuhn M (1981) Climate and Glaciers. International Association of Hydrological Sciences Publication, 131, 3-20

Leclercq PW and Oerlemans J (2012) Global and hemispheric temperature reconstruction from glacier length fluctuations. Clim. Dyn., 38(5-6), 1065-1079

Lowell TV (2000) As climate changes, so do glaciers. Proc. Natl. Acad. Sci. USA., 97(4), 1351-1354

Mackintosh AN, Anderson BM and Pierrehumbert RT (2017) Reconstructing climate from glaciers. Annu. Rev. Earth. Planet. Sci., 45, 649-680

Malone AG, Pierrehumbert RT, Lowell TV, Kelly MA and Stroup JS (2015) Constraints on southern hemisphere tropical climate change during the Little Ice Age and Younger Dryas based on glacier modeling of the Quelccaya Ice Cap, Peru. Quat. Sci. Rev., 125, 106-116

Medwedeff WG and Roe GH (2016) Trends and variability in the global dataset of glacier mass balance. Clim. Dyn., 48(9-10), $1-13$

Meier MF and Tangborn WV (1965) Net budget and flow of South Cascade Glacier, Washington. J. Glaciol., 5(41), 547-566

Mikkelsen TB, Grinsted A and Ditlevsen P (2018) Influence of temperature fluctuations on equilibrium ice sheet volume. Cryosphere, 12(1), 39

Mölg T and Hardy DR (2004) Ablation and associated energy balance of a horizontal glacier surface on Kilimanjaro. J. Geophys. Res. Atmos., 109(D16), D16104, 1-13

Oerlemans J (1986) An attempt to simulate historic front variations of Nigardsbreen, Norway. Theor. Appl. Climatol., 37(3), 126-135

Oerlemans J (1997) Climate sensitivity of Franz Josef Glacier, New Zealand, as revealed by numerical modeling. Arct. Alp. Res., 29(2), 233-239

Oerlemans J (2000) Holocene glacier fluctuations: is the current rate of retreat exceptional?. Ann. Glaciol., 31(1), 39-44

Oerlemans J (2001) Glaciers and climate change. CRC Press, Netherlands.

Oerlemans J (2003) A quasi-analytical ice-sheet model for climate studies. Nonlinear. Process. Geophys., 10(4/5), 441-452

Oerlemans J (2005) Extracting a climate signal from 169 glacier records. Science, 308(5722), 675-677

Oerlemans J and Fortuin J (1992) Sensitivity of Glaciers and Small Ice Caps to Greenhouse Warming. Science, 258(5079), 115-117

Oerlemans J and Hoogendoorn N (1989) Mass-balance gradients and climatic change. J. Glaciol., 35(121), 399-405

Oerlemans J and Reichert B (2000) Relating glacier mass balance to meteorological data by using a seasonal sensitivity characteristic. J. Glaciol., 46(152), 1-6

Oerlemans J and 10 others (1998) Modelling the response of glaciers to climate warming. Clim. Dyn., 14(4), 267-274

Penland C (2003) Noise out of chaos and why it won't go away. Bull. Am. Meteorol. Soc., 84(7), 921-925

Porter SC (1975) Equilibrium-line altitudes of late quaternary glaciers in the southern alps, New Zealand. Quat. Res., 5(1), 27-47

Rea BR (2009) Defining modern day area-altitude balance ratios (aabrs) and their use in glacier-climate reconstructions. Quat. Sci. Rev., 28(3-4), 237-248

Réveillet M, Rabatel A, Gillet-Chaulet F and Soruco A (2015) Simulations of changes to glaciar Zongo, Bolivia (16 s), over the 21 st century using a $3-d$ full-stokes model and cmip5 climate projections. Ann. Glaciol., 56(70), 89-97

Roe GH (2011) What do glaciers tell us about climate variability and climate change?. J. Glaciol., 57(203), 567-578
Roe GH and Baker MB (2014) Glacier response to climate perturbations: An accurate linear geometric model. J. Glaciol., 60(222), 670-684

Roe G and Lindzen R (2001) A one-dimensional model for the interaction between continental-scale ice sheets and atmospheric stationary waves. Clim. Dyn., 17(5-6), 479-487

Roe GH and O'Neal MA (2009) The response of glaciers to intrinsic climate variability: observations and models of late-Holocene variations in the Pacific Northwest. J. Glaciol., 55(193), 839-854

Roe GH, Baker MB and Herla F (2017) Centennial glacier retreat as categorical evidence of regional climate change. Nat. Geosci., 10(2), 95-99

Rupper S and Roe G (2008) Glacier changes and regional climate: a mass and energy balance approach. J. Clim., 21(20), 5384-5401

Sagredo EA, Rupper S and Lowell TV (2014) Sensitivities of the equilibrium line altitude to temperature and precipitation changes along the Andes. Quat. Res., 81(2), 355-366

Vacco DA, Alley RB and Pollard D (2009) Modeling dependence of moraine deposition on climate history: the effect of seasonality. Quat. Sci. Rev., 28(7), 639-646

Vaughan D and 13 others (2013) Observations: Cryosphere, book section 4, 317-382. Cambridge University Press, Cambridge, United Kingdom and New York, NY, USA, ISBN 978-1-10766182-0 (doi: 10.1017/CBO9781107415324.012)

Yang K and Jiang D (2017) Interannual climate variability change during the Medieval Climate Anomaly and Little Ice Age in PMIP3 last millennium simulations. Adv. Atmos. Sci., 34(4), 497-508

Zemp M and 6 others (2013) Glacier mass balance bulletin no. 12 (2010-2011)

Zemp M and 10 others (2015) Historically unprecedented global glacier decline in the early 21 st century. J. Glaciol., 61(228), 745-762

\section{APPENDIX A.}

The conditions for a mass-balance asymmetry can be demonstrated using the simplified mass-balance model presented in Roe and O'Neal (2009), which has been utilized subsequently to assess the transient response of glaciers to interannual variability (Huybers and Roe, 2009; Roe and Baker, 2014; Roe and others, 2017; Herla and others, 2017). The key assumptions within the Roe and O'Neal (2009) mass-balance model are the same as in this study, except that in this study there is a small accumulation gradient $\left(0.1 \mathrm{~m}\right.$ w.e. $\mathrm{a}^{-1} 100$ $\mathrm{m}^{-1}$ ) whereas in the Roe and O'Neal (2009) model there is no accumulation gradient. The mass-balance asymmetry in this study emerges due to the temperature-threshold melt model: Ablation $=\overline{\text { melt rate }} \times$ melt area. Melt occurs at all evaluations below the ablation season freezing-level-height $\left(A_{T>0^{\circ} \mathrm{C}}\right)$ at a melt-rate dictated by how much the air-temperature is above the temperature threshold $\left(0^{\circ} \mathrm{C}\right)$. For complete details for the model derivation, please consult Roe and O’Neal (2009).

Assuming the air-temperature follows a linear lapse $(\Gamma)$ from the summit $(x=0)$ to the terminus $(x=L)$ and that the glacier has a constant width $(w)$ and is on a constant slope $(\theta)$, the ablation model can be expanded as follows:

$$
\begin{aligned}
\text { Ablation }= & \frac{1}{2} \mu\left(T_{0}+\Gamma \tan (\theta) L\right) \\
& \times\left[w\left(L-\left(\frac{-T_{0}}{\Gamma \tan (\theta)}\right)\right)\right]
\end{aligned}
$$

where $T_{0}$ is the summit air-temperature during the ablation season. Equation (A 1) is only valid if the summit air-temperature is below the freezing since otherwise, the ablation area will exceed the area of the entire glacier. If portions of the 
glacier are below freezing, then there are two mass-balance gradients in the mass-balance profile: (1) a non-zero value in the melt region and (2) a zero value above the freezing-level height. Within both the Roe and O'Neal (2009) model and the methods used in this study, to produce a linear massbalance profile, the average ablation-season summit air-temperature must be above freezing, in which case the ablation model must be updated so that the melt area does not exceed the total area. The Roe and O'Neal (2009) model can be modified as follows:

$$
\begin{aligned}
& \text { Ablation }= \\
& \begin{cases}\frac{1}{2} \mu\left(T_{0}+\Gamma \tan (\theta) L\right) \times\left[W\left(L-\left(\frac{-T_{0}}{\Gamma \tan (\theta)}\right)\right)\right] & T_{0}<0^{\circ} \mathrm{C} \\
\frac{1}{2} \mu\left(2 T_{0}+\Gamma \tan (\theta) L\right) \times[W L] & T_{0} \geq 0^{\circ} \mathrm{C}\end{cases}
\end{aligned}
$$

Perturbing the climate around a mean summit air-temperature: $T_{0} \rightarrow T_{0}+T^{\prime}$, yields:

$$
\begin{aligned}
\text { Ablation }_{T_{<0}{ }^{\circ} \mathrm{C}}= & \frac{1}{2} \mu\left(T_{0}+\Gamma \tan (\theta) L\right) \times\left[W\left(L-\left(\frac{-T_{0}}{\Gamma \tan (\theta)}\right)\right)\right] \\
& +\mu T^{\prime} \times\left[w\left(L-\left(\frac{-T_{0}}{\Gamma \tan (\theta)}\right)\right)\right] \\
& +\mu T^{\prime} \times\left[w\left(\frac{T^{\prime}}{\Gamma \tan (\theta)}\right)\right]
\end{aligned}
$$

$$
\begin{aligned}
\text { Ablation }_{T_{\geq 0}{ }^{\circ} \mathrm{C}}= & \frac{1}{2} \mu\left(2 T_{0}+\Gamma \tan (\theta) L\right) \times[w L] \\
& +\mu T^{\prime} \times[w L]
\end{aligned}
$$

In both Eqns (A3) and (A4), the first term $(\mathcal{O}(0))$ describes the ablation for the mean climate, and the second term $(\mathcal{O}(1))$ describes the ablation anomalies due to changes in the melt rate for the melt area for the mean climate. The $(\mathcal{O}(0)$ ) helps define the mean state, but it is not affected by fluctuations in temperature around the mean. The $(\mathcal{O}(1)$ )-term is symmetric and does not affect the mean state. In both this modeling study and the model discussed in the Appendix, an $\mathcal{O}(2)$-term only emerges in the case where the summit air-temperature is below the freezing point (Eqn (A 3)), which is the case where the mass-balance profile has curvature. The $\mathcal{O}(2)$-term is the product of the anomalous melt rate and the anomalous melt area. For a constant valley width glacier, this term grows quadratically with air-temperature perturbations. This $\mathcal{O}(2)$-term is the source of the asymmetry in both this simplified analytical model and the idealized numerical modeling in this study. For the glacier with the constant linear mass-balance profile, the $\mathcal{O}(2)$-term does not appear (Eqn (A 4)), and there would not be a mass-balance asymmetry. The functional form of the asymmetry may differ depending on the valley geometry, but within this study there must be curvature in the mass-balance gradient for there to be a mass-balance asymmetry. 